\title{
Innovations of Web-based E-Erudition using Pedagogical Theory Aspects
}

\author{
P.Arumugam ${ }^{1}$, Dr.T.Krishnakumar ${ }^{2}$, Dr.M.Sriram ${ }^{3}$ \\ \{ ararun513@gmail.com ${ }^{1}$,drkk@bharathuniv.ac.in ${ }^{2}$, msr1sriram@gmail.com ${ }^{3}$ \}
}

\begin{abstract}
Research Scholar, CSE, Bharath Institute of Higher Education and Research, Chennai, India ${ }^{1}$, Professor, CSE, Bharath Institute of Higher Education and Research, Chennai, India. ${ }^{2}$, Assistant Professor, Department of CSE, Bharath Institute of Higher Education and Research, Chennai ${ }^{3}$
\end{abstract}

\begin{abstract}
In this technical international, Erudition comfort of E-Erudition . E-Erudition is prosperous a extensive in website results in treasured studying. It is stated the deliberate use of network material communication era coaching erudition. Webprimarily based E-Erudition gives teachers to elevate protection-associated understanding and competence. E-Erudition web sites indicates its wonderful evolution in instructive field and it need to please all of the pedagogical attributes. Pedagogy mentions to the precise use of informative techniques. The internet site that contents the Pedagogical attribute ought to measured groundbreaking E-Erudition website. The internet site has to be check in regards Erudition targets with the subject sorts as Knowledge, Attitude, and Skill, Meta-getting to know and Pedagogical strategies with the subject kinds as Drill, Presentation, Tutorials, Gaming, and Protest the usage of Pedagogical Attribute. Erudition objective and Pedagogical strategies of Pedagogical attribute are actual critical in the net doorway to offer the E-Erudition in extra powerful way. The fundamental goal of this rag is to make E-Erudition websites prosperous in studying. This paper has made a examine approximately the attribute of Pedagogical illustration and a case look at approximately how operative; the E-Erudition has been made with "Education" column of 'W3school' internet portal (online).
\end{abstract}

Keywords: E-Erudition, Pedagogy, Web based erudition , Instructor, Teaching.

\section{Introduction}

E-Erudition contains all types of automatically upheld erudition and educating. The data and correspondence frameworks, if networks, fill in explicit broadcasting, which incorporates web based erudition, cybernetic erudition, dispersed erudition, organization and electronic erudition [1]. Principally, allude to instructive cycles that use data and correspondences innovation. It tends to act naturally paced or teacher drove and incorporates media as text, picture, movement, real time video and sound. In E-Erudition , training is speedily cumulative and online doctoral schemes have uniform changed at heavy examination college.

E-erudition obtainable a few likely advantages over online erudition : The capacity to contact a wide crowd momentarily, Cost investment funds over homeroom based preparing, Measurable outcomes income up and execution, the possibility to make a local area of Estudents. These are the difficulties and advantages that make E-erudition achievement. 
$\mathrm{W} 3$ school is a site students a premium electronic erudition. The W3school website is stayed by electronic students a greater amount of a premium regular students. The website gets the condensing for the www; W3 is a numeronymg of WWW. It is made and possessed by Rejfsnes Data, Norwegian family-claimed programming advancement and counseling organization. The site generally comprises of novice's instructional exercises and orientations of the fundamental subject and dialects. It's astonishing data this site pack in a little spot. You peruse recently distributed programming book here [3]. W3school is quite possibly the greatest admired and regarded assets for online instructional exercises. W3 Schools awesome in cover exceptional instructional exercises on any language that the students need to learn. Alongside these instructional exercises, W3 Schools empowers students to cooperate with different segments, can rehearse perusing.

E-Erudition ought to be accomplished complete the instructive properties. It must be executed in the E-Erudition sites. In this way, e-students organizers can accomplish comfort in erudition .

\section{Classification of Pedagogical attributes}

The idea of E-Erudition arisen uniquely through recent year because of trading information amongst understudies, commercial associations, administration etc[11]. Specifically worry on E-Erudition expanded because of development web. The survey of E-Erudition is done now. Academic credits [9] are characterized into 3 classifications, Erudition Objective, Pedagogical techniques and Erudition Object. Every class numerous Topic type like Knowledges, Boldness, and Ability, Meta-erudition Etc[12]..

\section{Case study}

Teaching method, alluded right utilization educational procedures. In relationship with those informational systems, the educator's own philosophical convictions guidance are held and represented student's involvement information and experience, circumstance, and climate, just as knowledge objectives set by the student and organizer [2].

The e-erudition key subjects are knowledge goals and educational techniques. They depended on kind of the point, subject affiliations and its events [8]. The table 1 portrays the erudition destinations and educational strategies. 


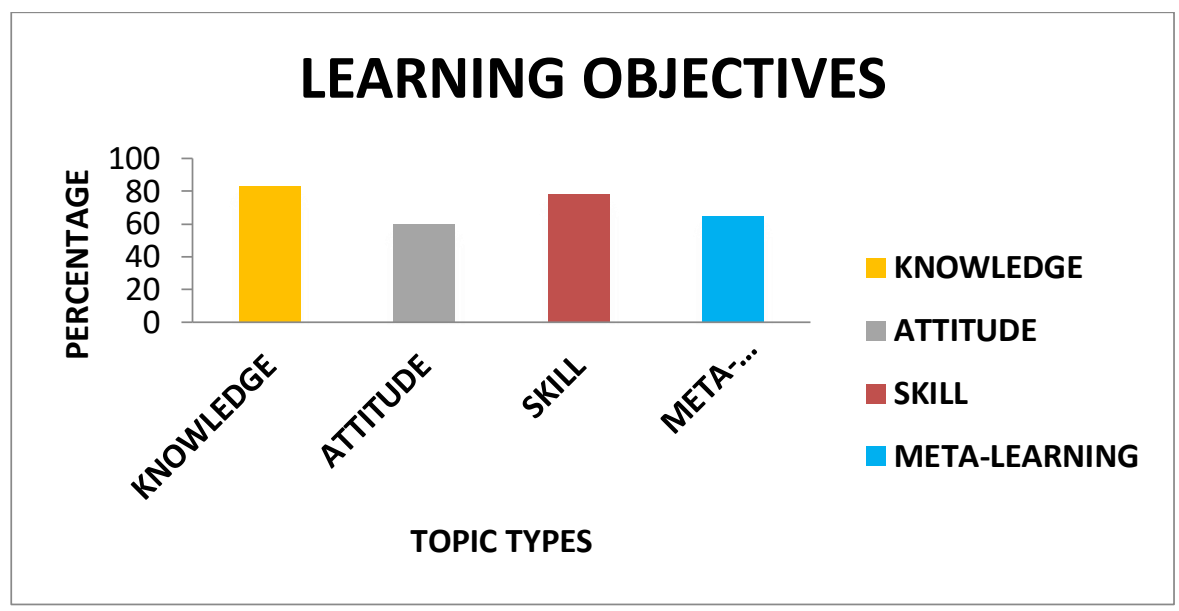

Chart 1: Erudition Objectives

Chart1 addresses the erudition goals where information is $84 \%$, demeanor is $61 \%$, expertise is $79 \%$ the meta-erudition is 66\%[13]. On a normal of the point type, information, demeanor, ability and meta-taking in estimated as $73 \%$ the input.

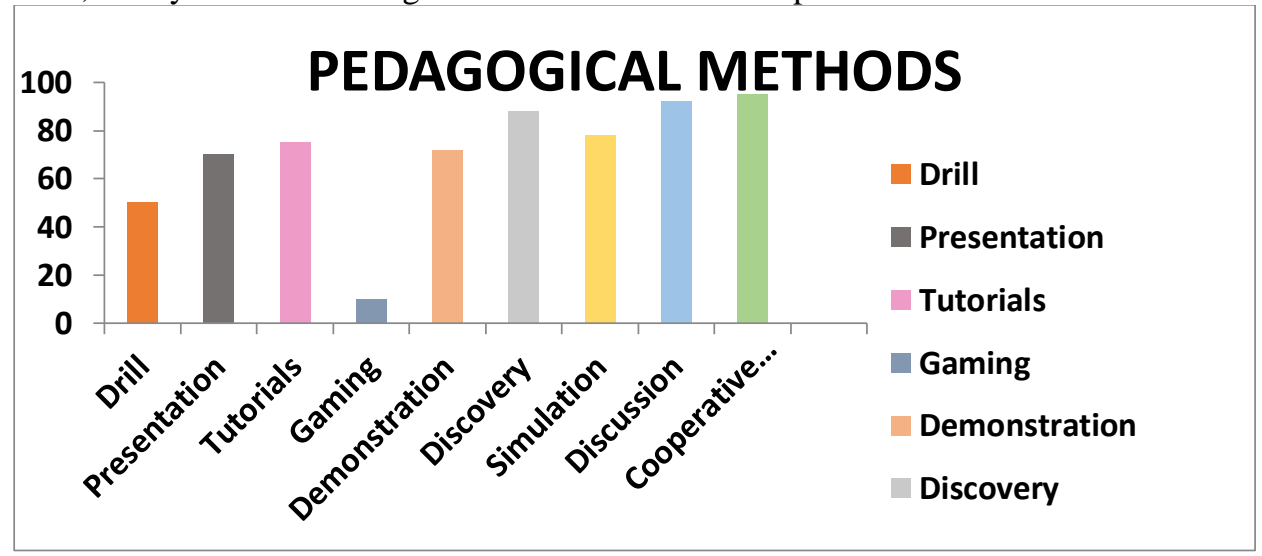

Chart 2: Pedagogical methods

Chart2 addresses the Pedagogical techniques wherein the theme type seen finished the variables of Drill[14], Arrangement, Tutorial, Game, demonstration, Detection, Imitation, Conversation, Obliging erudition .

From the exceeding diagram 2 we see that the Drill - half, Performance - 71\%, Tutorial $76 \%$, Game $-11 \%$, exhibit - 73\%, Detection - 89\%, Imitation - 79\%, Conversation - 93\%[15], Obliging erudition $-96 \%$. 


\section{Conclusion}

E-erudition site depends on the maxim that the erudition happens anyplace, whenever. The abilities for obtaining information assume a larger part in progress than information ideas. It is getting progressively unmistakable in instructive sites. E-erudition as an educational issue has carried numerous advantages to students. The instructive quality builds up a thick compatibility among the student and the facilitator. Among the most apparent and important properties of e-erudition strategies and conveyance is that they possibly give students more prominent admittance to schooling, in contrast with conventional erudition . The sites that are created by fulfilling every one of the qualities of the academic techniques is viewed as the greatest and furthermore it sparkles well. The examination on the "W3school" clarifies that more instructive traits fulfilled remember profundity for ascribes like Attitudes, Metaerudition , Drill, Performance and Game. On off chance that the E-Erudition sites fulfills every one of the instructive traits which has been referenced in this investigation, at that point it is careful as the respected E-Erudition sites. Upcoming examination can prompt every one of the fields of the site, recognizable proof of absence of instructive traits in the entryway, ideas to recover the E-erudition sites can likewise be incorporated.

\section{References}

[1] McGhee, R. and Kozma, R. (2003). New Teacher and Student Roles in the TechnologySupported

[2] Classroom Available: http: //edtechcases.info /papers/ teacherstudentroles.pdf

[3] Britain, S. and Liber, O. (2004). A Framework for the Pedagogical Evaluation of eErudition Environments. http://www.cetis.ac.uk/members/pedagogy/files/4thMeet_framework/VLEfullReport

[4] http://en.wikipedia.org/wiki/W3school

[5] Salmon, G. (2000). E-moderation - The Key to Teaching and Erudition Online. Kogan Page, 0-7494-3110-5

[6] Itmazi, J. A. and M. M. Gea (2005). Survey: Comparison and Evaluation Studies of Erudition Content Management Systems. MICROERUDITION 2005: Erudition \& Working in New Media Environments. International Conference, Innsbruck, Austria.

[7] Woelk, D. (2002, June). E-erudition : Semantic Web services and competency ontologies. In Proceedings of ED-Media 2002 Conference.

[8] Kljun, M., J. Vicic, et al. (2007). Evaluating Comparisons and Evaluations of Erudition Management Systems. Proceedings of the ITI 2007 29th Int. Conf. on Information Technology Interfaces, Cavtat, Croatia, IEEE.

[9] Piccoli, G., Ahmad, R., \& Ives, B. (2001). Web based virtual erudition environments: a research framework and a preliminary assessment of effectiveness in basic IT skills training. MIS Quarterly, 25, 401-427.

[10] Line Kolås (2008). Topic Maps in E-erudition : An Ontology of Computer and Information Science.

[11] Dr. Kaliyamurthie K.P "An Application Of Non-Uniform Cellular Automata For Efficient Cryptography”, Indian Journal of Science and Technology, Vol 6, Issue 5S, page 4648-4652 May 2013.

[12] Dr. Kaliyamurthie K.P "K-Anonymity Based Privacy Preserving For Data Collection In Wireless Sensor Networks", Indian Journal of Science and Technology, Vol 6, Issue 5S, page 4604-4614 May 2013.

[13] Dr. Kaliyamurthie K.P "Highly Secured Online Voting System Over Network" , Indian Journal of Science and Technology, Vol 6, Issue 6S page 4831-4836 May 2013. 
[14] T. Vijayan , M. Sangeetha , A. Kumaravel \& B. Karthik (2020): FeatureSelection for Simple Color Histogram Filter based on Retinal Fundus Images for DiabeticRetinopathy Recognition, IETE Journal of Research, DOI: 10.1080/03772063.2020.1844082.

[15] D. S. Vijayan, A. Leema Rose, S. Arvindan, J. Revathy, C. Amuthadevi, “Automation systems in smart buildings: a review", Journal of Ambient Intelligence and Humanized Computing https://doi.org/10.1007/s12652-020-02666-9

[16] Vijayan T, Sangeetha M, A. Kumaravel, Karthik B, "Gabor filter and machine learning based diabetic retinopathy analysis and detection", Microprocessors and Microsystems,2020. https://doi.org/10.1016/j.micpro.2020.103353.

[17] Vijayan T, SangeethaM, Karthik B, "Trainable WEKA Segmentation of Retinal Fundus Images for Global Eye Disease Diagnosis Application," International Journal of Emerging Trends in Engineering Research,Vol 8, No.9, pp. 5750-5754, Sep 2020. https://doi.org/10.30534/ijeter/2020/136892020

[18] C. Amuthadevi, D. S. Vijayan, Varatharajan Ramachandran, "Development of air quality monitoring (AQM) models using different machine learning approaches", Journal of Ambient Intelligence and Humanized Computing, https://doi.org/10.1007/s12652-020-02724-2

[19] Vijayan T, Sangeetha M, A. Kumaravel, Karthik B, "Fine Tuned VGG19 Convolutional Neural Network Architecture for Diabetic Retinopathy Diagnosis," Indian Journal of Computer Science and Engineering (IJCSE), Vol. 11, No. 5, pp. 615-622 Sep-Oct 2020. DOI: 10.21817/indjcse/2020/v11i5/201105266.

[20] Vijayan T, Sangeetha M, Karthik B, "Efficient Analysis of Diabetic Retinopathy on Retinal Fundus Images using Deep Learning Techniques with Inception V3 Architecture,” Journal of Green Engineering, Vol 10, Issue 10, pp. 9615-9625. Oct 2020 